\title{
Diacyllipid Micelles-based Nanocarrier for Magnetically Guided Delivery of Drugs in Photodynamic Therapy
}

\author{
Ludmila O. Cinteza ${ }^{l}$, Tymish Y. Ohulchanskyy ${ }^{l}$, Yudhisthira Sahoo ${ }^{l}$, Earl J. Bergey ${ }^{l}$, \\ Ravindra K. Pandey ${ }^{1,2}$ and Paras N. Prasad ${ }^{1}$. \\ ${ }^{1}$ Institute for Lasers, Photonics and Biophotonics,SUNY at Buffalo, Buffalo, New York 14260 \\ ${ }^{2}$ Photodynamic Therapy Center, Roswell Park Cancer Institute, Buffalo, New York, 14263
}

\section{SUPPORTING INFORMATION}

Cell viability assay. For studying cell-viability, 24-well plates were inoculated with cells $\left(7.5 \times 10^{5}\right.$ cells/well) and incubated overnight. The medium was removed; the wells were rinsed three times using sterile PBS, and $2 \mathrm{ml}$ of fresh medium was added to each well. Pre-determined concentrations of drug in polymeric micelle, (determined using UV-Vis absorbance measurements) were added to designated wells.

The plates were then returned to the incubator for two hours. Next, the wells were rinsed three times with sterile PBS. $2 \mathrm{ml}$ of the fresh medium was added and the wells were immediately exposed to a $650 \mathrm{~nm}$ laser light source for 10 minutes each. The optical intensity at the cell level was $\sim 1.4 \mathrm{~mW} / \mathrm{cm}^{2}$. The plates were returned to the incubator overnight. Cell viability was estimated by means of the colorimetric MTT assay. In the MTT assay, the absorbance of formazan (produced by the cleavage of MTT by dehydrogenases in living cells) at $570 \mathrm{~nm}$ is directly proportional to the number of live cells. 
Briefly, MTT was dissolved in sterile PBS at $5 \mathrm{mg} / \mathrm{ml}$, and $200 \mu \mathrm{l}$ was added to each well. The plate was then incubated at $37^{\circ} \mathrm{C}$ with $5 \% \mathrm{CO}_{2}$ for 4 hours. After incubation, the medium was carefully aspirated and any purple MTT formazan crystals were dissolved in $2 \mathrm{ml}$ of $0.1 \mathrm{~N} \mathrm{HCl}$ in anhydrous isopropanol. The absorbance was measured at $570 \mathrm{~nm}$, using a Bausch \& Lomb Spectronic 601 spectrophotometer. Cells incubated with serum-supplemented medium only represent $100 \%$ cell survival. Four fold replicates were run per drug and light dose, and each experiment was repeated three times.

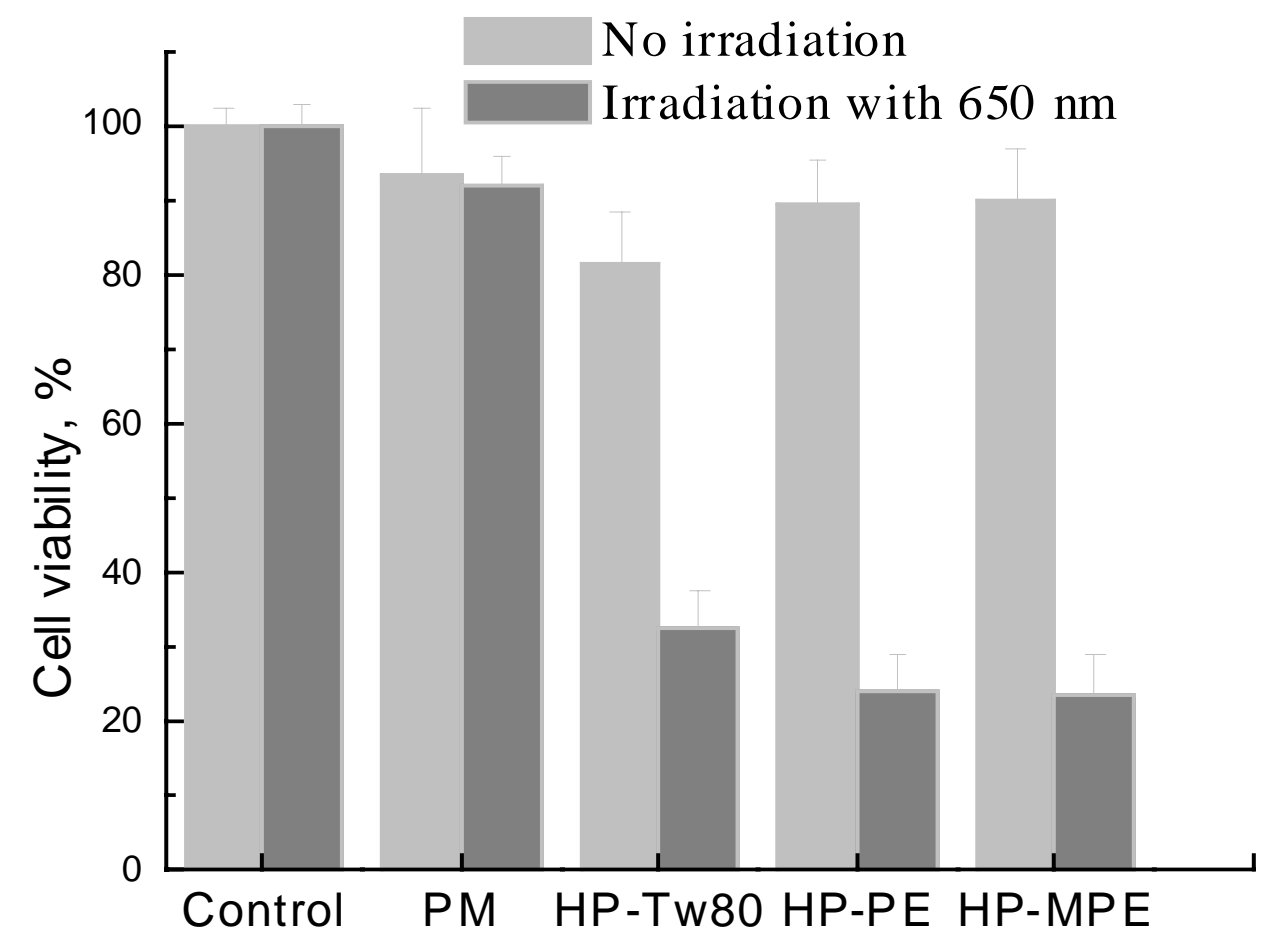

Figure S1 Percentage cell-survival of Hela cells incubated with various agents (relative to cells incubated with supplemented media, control) and subsequently irradiated by suitable light, as assayed by MTT method. PM - void PEG-PE micelles; HP-Tw80 HPPH in Tween-80 micelles; HP-PE - HPPH in PEG-PE micelles; HP-MPE - HPPH in PEG-PE micelles containing magnetic nanoparticles. Amount of HPPH was equalized spectrophotometrically at the wavelength of excitation $(650 \mathrm{~nm})$. 